\title{
The Integration of Fiqh Psychology in Curriculum: Muslim Community Healthcare in Singapore
}

\author{
Nek Mah Binte Batri \\ PUSAT PENDIDIKAN AN NIKMAH, SINGAPORE \\ nek_mahb@hotmail.com
}

\begin{abstract}
The integration of Fiqh Psychology in curriculum is a response to the contradiction between the health trends of Malay/Muslim community and what their professed faith preaches. The religious mandate on the importance of personal healthcare has not permeated through. It begs the question of what more can be done from a socio-religious perspective to arrest this health trend, which has both current and long-term implications to the community's healthcare burden and impact on the national healthcare landscape. This paper attempts to explain this paradox, explores the problem through a series of case reports, highlights the lessons learnt and recommends further steps that can be explored as a community. The objective of the integration is to introduce, mould, remind and enhance the necessary Isla mic attributes to the Malay/Muslim community in Singapore. The methodology involves case examples to highlight how religious views may influence a person's outcome in healthcare. This is followed by a brief discussion pertaining to the individual tailoring of their possible applications in the curriculum. It is hoped that the integration of Fiqh Psychology in the curriculum not only can provide direction but will also enrich the character of the Malay/Muslim community towards the healthcare in Singapore.
\end{abstract}

Keywords: Fiqh Psychology, Healthcare, curriculum, integration.

\section{INTRODUCTION}

In recent years, there has been significant concern regarding the relative ill- health of Malay/Muslim in Singapore. Such is the magnitude of the problem that Prime Minister Lee Hsien Loong described it as a "health crisis" for Malay/Muslim in his 2017 National Day. The magnitude and extent of the health indicators for the Malay/Muslim community in Singapore are alarming compared to other communities, Malay/Muslim community have the highest rates of hypertension, high cholesterol, obesity, daily cigarette smoking, asthma and kidney impairment, and are a close second for diabetes behind other community. Therefore, the integration of Fiqh Psychology in curriculum is to shaping the minds of Malay/Muslim community. Basically, the integrate of Fiqh Psychology to make easier for the Malay/Muslim community to learn other than medication to help with the illness, it's also required to have sound of Fiqh Psychology (Naqly and Aqli).

In addition to the objective of integrating Fiqh Psychology)in the curriculum isemphasized in Malay/Muslim community healthcare in order to manifest the gap between morality and fiqh that require careful judgement. It encompasses the appreciation an understanding of the Fiqh Psychology issues of health and disease, the social aspects of medical practice and the conduct of research and adherence to Islamic professional etiquettes.

One of the principles of the integration is the princ iple of relevance. The Fiqh can only serve as the interpretive enterprise of Shari'ah in the case that the practise of "healthcare" is taking into account, along with due observation in upholding the principles of maqasid al Shari'ah itself. Whereas psychology is the science of behaviour and the physiological and cognitive processes associated with behaviour. Psychology is also the profession that applies the science of behaviour to practical problems. The cognitive perspective considers the role of the mind in behaviour, including how we perceive and represent the world, learn and remember information, and solves problems. This principle describes the objectives, learning process, needs and development of cognitive and Malay/Muslim community in Singapore.

\section{METHOD}

The curriculum is a guideline for the implementation of learning activities to achieve the education goals. This guideline includes content how the Malay/Muslim community need to learn them. The methodology involves case examples to highlight how religious views may influence a person's outcome in healthcare. This is followed by a brief discussion pertaining to theindividual tailoring of their possible applications in the curriculum.

This research is case examples, so the technique of date collection is document technique. The documents analyzed are from the interview with some of the 
respondent in the Malay/Muslim community in Singapore. For example, Madam A is a middle aged lady with a history of Panic Disorder. She was experiencing anxiety attacks while doing her Hajj and was struggling with her ibadah at the Holy Land, because she was feeling breathless and anxious from being around the crowds there. She was frequently tearful, felt a sense of worthlessness and frustration about herself. She was worried that her trip would be one fraught with difficulty and that her attempt at Hajj would be wasted and futile. She could never feel at ease, was hyper vigilant of her surroundings and her focus on ibadah was affected.

In other case, Mr B was a man in his late 40s and was told by his doctor that he was diagnosed with Diabetes. He was concerned about this finding and would come several times to the clinic just to check on his blood sugar levels. He could appreciate what his doctor had told him; that he was a newly diagnosed Diabetic, that there are medications he needs to take and that if uncontrolled, the complications of Diabetes can be debilitating. He felt, however, there were ways for him to manage his sugar levels without the need for medications, which his faith was "strong" enough to prevent worsening of his Diabetes and he could consider purely prophetic ways of healing such that his Diabetes would no longer be there. This approach, however, led to a disagreement between the physician and himself, as he frequented the clinic regularly to check his blood sugar levels but was adamant in his refusal to act on the deranged results.

$\mathrm{Mr} \mathrm{C}$ was a young teenager when he first had changes in his behaviour, which resulted in him being aggressive towards his family members. Otherwise an unassuming and friendly person, he would have moments where he would be confused, aggressive and agitated. This would be swing very quickly from a moment of calmness to extreme, disinherited behaviour leading to punching his family members, hearing voices in his head and paranoia towards others. His family was adamant that $\mathrm{Mr} \mathrm{C}$ was being spiritually disturbed; that someone was casting a spell or that it was the work of Iblis. It was inconceivable to them that it could be a medical presentation, or even an emergency. It was only once the family could not contain Mr C's behaviours that they brought him to a restructured hospital for treatment. Later, it was found that there were some chemical abnormalities in his blood and his brain to suggest the possibility of a brewing infection.

Lee Seng Esmond Seow, Mythily Subrmanian, Edinmasyah Abdin, Janhavi Ajit Vaingankar and Siow Ann from Research Division, Institute of Mental Health (IMH), Singapore (2015), have shown hypertension to be a common health problem among the elderly of Malay community. There is an increase in the number of Malays suffering from high blood pressure (Table 1).

Table 1. Mean systolic and diastolic blood pressure, and distribution of blood pressure classes by the Joint National Committee on Prevention, Detection, Evaluation, and Treatment of High Blood Pressure; overall and by age, gender, and ethnicity.

\begin{tabular}{|c|c|c|c|c|c|c|}
\hline & \multicolumn{2}{|c|}{ BP levels (mmHg), mean (SE) } & \multicolumn{4}{|c|}{ BP categories based on JNC-7. Weighted row, $n(\%)$} \\
\hline & SBP & DBP & Normal & High-Normal & Stage 1 & Stage 2 \\
\hline All & $141.4(0.6)$ & $75.2(0.3)$ & $316(13.4)$ & $1322(54.9)$ & $619(23.6)$ & $231(8.1)$ \\
\hline \multicolumn{7}{|l|}{ Age group (y) } \\
\hline $60-74$ & $140.8(0.7)$ & $76.5(0.4)$ & $187(13.9)$ & $840(56.8)$ & $337(22.7)$ & $97(6.7)$ \\
\hline $75-84$ & $143.8(1.1)$ & $72.2(0.6)$ & $66(10.9)$ & $330(51.5)$ & $178(25.6)$ & $78(12.0)$ \\
\hline $\begin{array}{l}85+ \\
\text { Gender }\end{array}$ & $142.6(1.6)$ & $68.7(0.8)$ & $63(16.3)$ & $152(40.6)$ & $104(28.3)$ & $56(14.8)$ \\
\hline Men & $141.0(0.8)$ & $76.8(0.5)$ & $152(12.6)$ & $588(55.8)$ & $276(24.5)$ & $82(7.2)$ \\
\hline Women & $141.8(0.8)$ & $74.0(0.4)$ & $164(14.1)$ & $734(54.2)$ & $343(22.9)$ & $149(8.8)$ \\
\hline \multicolumn{7}{|l|}{ Ethnicity } \\
\hline Chinese & $140.9(0.7)$ & $74.9(0.4)$ & $138(13.9)$ & $525(54.9)$ & $238(23.1)$ & $93(8.2)$ \\
\hline Malay & $148.1(0.9)$ & $78.4(0.5)$ & $61(7.5)$ & $384(56.4)$ & $185(26.3)$ & $84(9.8)$ \\
\hline Indian & $139.9(0.8)$ & $75.5(0.4)$ & $112(15.3)$ & $397(55.1)$ & $183(23.1)$ & $53(6.6)$ \\
\hline Others & $138.6(2.7)$ & $73.2(2.4)$ & $5(14.9)$ & $16(47.1)$ & $13(36.5)$ & $1(1.6)$ \\
\hline
\end{tabular}
$\mathrm{SBP}=$ systolic blood pressure.

While satisfaction with religious leadership is positive, it is interesting to note that more than a third of Malay/Muslim still feels that religious teachers are failing to keep in touch with young Malay/Muslim (see Chart 1). This is an important finding, considering the community's broader concerns about youth behaviour and moral deterioration. Considering Malay/Muslims' concerns about youth delinquency, it is notable that more than a third of them felt that asatizahs are not in touch with young Malay/Muslim. An equal percentage of key influencers (42\%) also indicated so (see Chart 2). 


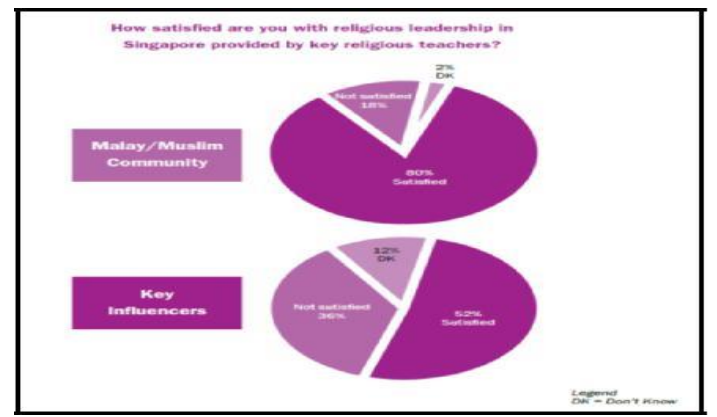

Chart 1: Islamic Leadership Resource AMP (2011) Malay/Muslims

\section{RESULT}

Other than medications to help with Madam A anxiety, the doctor she visited at the Holy Land was able to reason with her that, from a religious angle, her state of emotional turbulence, anxiety and inner restlessness stemmed from a deeper desire and sincere intention to be closer to Allah in her ibadah - a state of being that other "normal" people struggled to connect with. It was suggested to Madam A that her propensity to be easily emotional was something that could be seen as a "gift", in fact, advantageous for her ibadah. After the consult, Madam A appeared calmer and completed the rest of her Hajj obligations without incident. With her newfound religious perspective, she felt more accepting of her intermittent worries, ironically even feeling more in control of her symptoms than before. This intervention, rooted in religious understanding, complemented her pharmacological management well and had a good outcome in her care.

Mr B indeed acknowledged the medical basis of a physical illness like Diabetes. However, even as he appeared to accept this model of illness, he was selective about seeking treatment propagated by the same medical model, instead believing in more "religious", "traditional" or "natural" ways of healing. There may also be a propensity for the patient to actually accept the diagnosis but preferring to leave the treatment "in the hands of God" alone, without the patient having to take medications as an effort on his part. This potentially delays treatment, worsens prognosis and makes an illness, otherwise preventable and potentially cured, potentially life-threatening instead.

In Mr C's case, religious beliefs were well rooted in his family but their strong convictions about spiritual beings and disturbances clouded their judgment and understanding on what was happening - an infection of the brain resulting in his odd behaviours. This prevented early treatment and allowed for his symptoms to worsen, until it was really difficult to manage at home. Another variation of such religiously-themed barriers to medical treatment include the strong conviction of some segments of the population towards spiritual healers, traditional methods of healing and purported "natural" remedies that offer quick resolution of symptoms. These claims are not

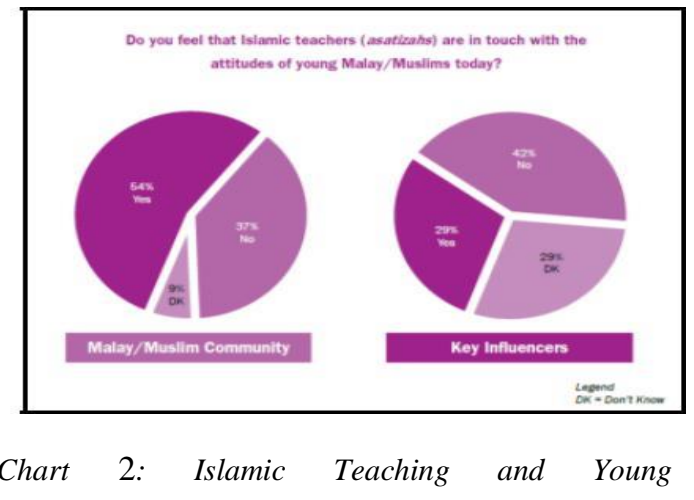

necessarily without basis, especially the steroid-based remedies, which subjectively give an added boost of "wellness" and "energy" in the short term but are inevitably short-lived, do not address the root cause of the illness and are potentially harmful with long term use.

The integrated of Fiqh Psychology must be implemented in the curriculum as the existing dogmatic mindset among groups and individuals in Malay/Muslim societies. There are even certain Malay/Muslim scholars who uphold the belief that the structure of Islamic intellectual traditions were already well developed by the classical scholars, and have always been skeptic towards all new proposals for the renewal of the legal tradition. This type of frozen mindset needs to be faced wisely in order to bring healthcare discourse within the sphere of Is lamic jurisprudence (Fiqh). This is in accordance with the results of the above research.

\section{CONCLUSION}

There could be a few reasons why Malay/Muslim has poor ill- health even though Islam preaches the importance of healthcare. The dichotomous narrative between religious and secular matters reinforces the artificial divide that duty to personal health has neither overlap nor place within religious domains. For those without a strong affinity to religion, they would not view healthcare, dieting, exercise or medical treatment as something even remotely religious. Taking care of their health is then seen only as a personal endeavor at best, and not within the ambit of any form of religious influence. There are traditional belief systems within the Malay/Muslim community that may hinder a more nuanced understanding and acceptance of the medical model of illness. These include a preference for spiritual or religious explanations of illness, to view "traditional", "natural" and "non-Western" medications as more authoritative and efficacious, and that spiritual faith and treatment alone are sufficient to ward off all manner of illnesses. There is a lack of conversation and a structured collaborative partnership between Muslim religious leaders and medical doctors. Many Muslim doctors also may lack the nuance and confidence in appreciating religious affairs, at least enough to reasonably defend a theological challenge to their medical knowledge or gain quick reference to someone. 
Healthcare, like religious duty, is a very personal and internally driven matter. They are often seen as separate fulfill his ibadah can be affected. Furthermore, if personal healthcare is seen through the lens of the amanah to take care of one's physical body in this world, then certainly the religious emphasis on personal healthcare will carry more weight and drive behaviours towards better healthcare. The willfully unhealthy Malay Muslim is a paradox because a lackadaisical approach to personal health is not what Islam encourages nor permits. While a religious focus towards healthcare may not necessarily convert all Malays to eating healthily and exercising regularly, it will trigger a renewed innate sense of duty and obligation towards their personal health that was not previously emphasised. In the longer term, this strategy will drive a more sustained health-conscious behaviour and improve the community's healthcare indicators significantly over time. issues, yet they both impact each other significantly. Illhealth may debilitate a person such that his ability to

\section{REFERENCES}

[1] Karyawan, Published by: Association of Muslim Professionals 2009.

[2] Ministry of Health,"Diabetes Action Now: An initiative of the World Health Organization and the international, Diabetes Federation 2011.

[3] Ministry of National Health Survey (2004 and 2010)

[4] Research Division, Institute of Mental Health, Singapore, "Hypertension and its associated risks among Singapore elderly residential population 2015.

[5] The Association of Muslim Professionals (AMP), "Perception Survey on the Malay/Muslim Community in Singapore 2011. 
